\title{
The study of the collaborative regulatory indemnification mechanism of the higher education quality in China
}

\author{
Wu Yun-na \\ School of Economics and Management, NCEPU \\ 102206 \\ Beijing, China \\ wu_yunna@163.com \\ Wang Qing \\ School of Economics and Management, NCEPU \\ 102206 \\ Beijing, China \\ w20070627@126.com
}

\author{
Tan Lei \\ School of Economics and Management, NCEPU \\ 102206 \\ Beijing, China \\ hdtanlei@163.com
}

\begin{abstract}
The various components of your paper [title, text, heads, etc.] are already defined on the style sheet, as illustrated by the portions given in this document. In our country, with the development of the higher Education, there are more and more students attend the higher education now, which brings many problems to its quality. The collaborative regulatory system of higher education, which includes the training unit self-control system and multi-party participation in lateral system of supervision, can manage the quality of higher education in a comprehensively of the whole process and full participation way which can effectively control the quality of higher education. However, how to ensure the implement of the collaborative regulatory system has become the key to the quality of higher education. Therefore in this article mainly study the collaborative regulatory from the two aspects of the training unit and multi-party participation, to guarantee the stability and effective implementation of the regulatory system and ultimately improve the quality of higher education.
\end{abstract}

Keywords-component; formatting; style; styling; insert (key words the quality of higher education, collaborative regulatory, indemnification mechanisms

\section{INTRODUCTION)}

The goal of the higher education is to provide useful person to society, and the final level of the knowledge students gained in school reflects the quality of higher education. At present, China's higher education has changed from the "elite education" to the "popular education", which causes many problems, such as the shortage of university resources, student high employment pressure and so on. These problems seriously affect the quality of higher education in China, so the gradual strengthening of the indemnifications system and the improvement of the quality of higher education has become the key to the development of higher education in China in future.

Monitoring the quality of higher education is to take a series of measures to strictly monitor and manage the various activities in the training process after meeting the requirements of higher education required resources according to the Higher Education training plan, which can correct occurrence of the deviation and sum up experience to ensure the achievement of the higher education training goals. Effectively monitoring and managing the quality of higher education can be used to find the problems in the process of higher education, and provide indemnification system to improve the quality of higher education.

\section{THE COLLABORATIVE REgULATORY SYSTEM OF THE QUALITY OF HIGHER EDUCATION}

The supervision of the quality of higher education is systematic process engineering, and the quality of higher education should be the center of the supervision. Besides, the management thought of the supervision should focus on the quality of the training unit's self-control and participation units coordinated supervision to promote the holistic, dynamic nature of the whole process of the training quality management. The supervision of the quality of higher education should start from a project management perspective and adhere to the idea of integration and integrating a variety of regulatory resources and methods to ultimately achieve the integration of monitoring of the quality of higher education. That's to say, the collaborative regulatory system of the quality of higher education is a stereoscopic intersect system, which combine the longitudinal self-control system of training unit and the lateral supervision system of multi-party participation. For training unit's self-control system and multi-party participation's horizontal regulatory system, the control points are the same but the methods and measures are different during the quality control process.

1.1 The training unit longitudinal self-control system In accordance with the life cycle and the training stages of higher education, the quality control point of self-control units can be defined. There are quality control of admission stage, quality control of the training preparation phase; quality control of teaching stage, quality controls of paper 
stage, and quality control of degree-granting stage. That is the basic content of the training unit longitudinal selfcontrol system.

The responsibility of the training unit in the longitudinal self-control system is the quality control of the whole process of higher education. That's to say, the training unit control quality at internals, which plays an endogenous role in the entire regulatory system. Different stages play different roles and have different impacts in quality control of higher education, so there are different methods and measures in quality control of higher education.

1.2 The multiparty lateral regulatory system

Lateral monitoring system is that the parties related to the whole process of the higher education supervise and manage the quality of higher education in accordance with the training objectives of it. The main parts of the supervision to create synergies regulatory system is government education departments, social masses and employer. As for the government's level, it is mainly the departments in charge of education, which include the Ministry of Education, Ministry of Finance, the National Audit Office, and the State Council Academic Degrees and so on. The government regulates the introduction of relevant policies on higher education on the basis of a comprehensive evaluation of the quality of higher education according to the results of the feedback. As for the social's level, the social masses supervise the quality of the whole process of higher education, and timely give feedbacks about the problems they find and views of quality improvement to the education sectors. As for the level of employer, Employer evaluate the graduates according to the student's performance and the ability to work, and then give the results to the colleges and the education sector after college graduates work for some time in the company, which can help to improve the quality of higher education.

The parties involved in the process of the horizontal regulatory of the quality of higher education should have clear regulatory responsibilities, and effectively restrict and stimulate the quality within the inherent constraints and incentives. However, the parties should minimize the unnecessary regulatory aspects and the overlap regulatory of higher education to guarantee the achievement of the overall goal of quality.

\section{COLLABORATIVE REGULATORY INDEMNIFICATION MECHANISMS OF THE QUALITY OF HIGHER EDUCATION}

\section{A. training units' internal indemnification mechanisms}

The training unit of the self-control system is essential to the coordinated supervision of the quality of higher education system, and its implementation has a direct impact on the realization of the goals of higher education. The implementation of the training unit's self-control system plays a key role in the implementation of the indemnification mechanism. Therefore, it is very important to strengthen the training of the unit's internal indemnification mechanisms. According to the emphasis the unit indemnification mechanisms can be divided into organizational indemnifications, policies, security, system security, positive and negative incentives indemnification and accountability indemnifications, which are shown in Figure 1.

(1) Organizational indemnification. Organizational guarantee is the organizational measures taken by the unit which can insure the training unit to do the sustained and effective research on the issues of higher education quality. The main contents include the follows. Training units should set up specialized offices with professional staff of higher education, which can better provide the services for the supervision indemnification of the higher education quality. The training units can organize experience-sharing sessions, symposia, seminars and other services regularly. Besides, they can organize staff to learn the knowledge of the regulation of the quality of higher education to help them better understand the quality of higher education regulatory system.

(2) Policy indemnification. The quality of higher education is reflected in the quality of talent person that training unit input for the social. Because the quality of the talent person decide an industry or even a country's future development, so training units play a direct and effective role in improving the quality of higher education. The introduction of the policy of the training units have a direct impact on the students who access to higher education, and the speed of the contents of the policy and the introduction directly affect the quality of higher education. Therefore, in order to ensure the quality of higher education, training units should give policies indemnification, which might in accordance with national policy and the introduction of appropriate social feedback timely. Besides, the policy should be consistent with the current situation and have a certain role in improving the quality of higher education.

(3) Institutional indemnification. The system is the regulations that a social organization or group requires its members to comply with according to certain procedures. As an old saying goes, no rules no behavior. That to say, a good system can help to restrict the behavior and moral of the units faculty and students in higher education, which can insure the good and stable implementation of the regulatory system of the training unit from the stage of enrollment in higher education, training preparation phase, curriculum stage dissertation stage to the stage of degree-granting.

(4) The positive and negative incentives indemnification. For higher education, the goal of the training unit's selfcontrol system is to improve the quality of its supervision and the final quality. When the goal is reached, the training unit should summarize the success factors, and take the corresponding positive incentives to continuous improvement of the higher education quality.

When the quality of higher education is declining or stagnating, training units should adopt incentives measures to ensure the personnel actively and seriously study to find the cause of the problem, and actively looking for solutions. In addition to this, the personal should as well as find the solution related problems seriously in order to prevent 
similar mistakes occurred again and finally guarantee the improvement of the quality of higher education.

(5) Accountability indemnifications. There will be a variety of problems during the period of the implementation of training unit's self-control system of the higher education quality. When problems or even accidents happened, training units should have a careful analysis of the problems and strictly investigated the related responsibility of the persons, which can effectively prevent the problem from happening again and to protect the better implementation of the selfcontrol system.

\section{B. Collaborative regulation of external indemnification mechanisms}

Participants are important participants and the direct stakeholders in the quality management of higher education .The quality of higher education to achieve success will have some impact on them in varying degrees, at the same time they also bear some responsibility for the quality of higher education. In the collaborative regulatory system in the quality of higher education, it can be mainly divided into three levels that are government, society and employers. This article will study the mechanism of indemnification of the quality of higher education regulatory system on three levels.

(1) Government security mechanism

The government is the country's governance and management of institutions to maintain and achieve specific public interest, public administrative powers to the country's armed forces backed with mandatory effect. Broad government is a collection of the three powers of the legislative, executive, judicial, and the U.S. government is a typical separation of political system, and therefore even within the government's regulatory also mutual restraint; the relative concentration of the powers of our government, by our national conditions, to improve the efficiency of decision-making through the unified leadership. Functions from the government point of view, the government level indemnification mechanisms can be divided into three aspects of the legislative, executive and judicial.

1) The legislation indemnification. The fundamental law of the Constitution states that one of the basic political system in China is governing the country according to law. The law is applicable to all organizations or individuals a within common code of conduct, violations of the law must be held accountable. For regulatory activities, it is necessary to comply with the basic spirit of the Constitution as the fundamental basis, but also to the legal system. Strengthen the regulatory legislative indemnification of government investment projects, according to the needs of the regulatory relationship adjustment, under the guidance of the spirit of the Constitution, to strengthen the construction and improvement of the building regulations, while focusing on the construction of supporting regulations and civil laws, administrative regulations and economic regulations, the regulatory oversight activities to carry out the law, but also to make the regulatory and oversight powers are protected by law and constraints.

Government legislative function to provide indemnification for regulators: provide the basis for government regulation, restrain government regulatory powers; adjust agent construction market economic relations, regulate agent construction market order; protect the rights of press supervision.

2) Administrative indemnification. The government is usually referred to the government narrowly, which is the executive organ of the State power to carry out the management of the public domain, and regulatory activities on the part of the government administrative affairs on behalf of the building project. Protect the government from the administrative aspects of the project construction supervision activities, fundamentally is necessary to introduce and improve the policies and systems at all levels of government and relevant national standards and norms. Implementation, will have to co-ordinate the planning and indemnification of the utilization of regulatory resources and regulatory team building, improve the regulatory capacity of the government department in charge of administrative, to establish a government regulatory authority.

Government administrative functions to provide regulatory indemnification embodied: regulatory activities for all levels of government and the competent authorities to carry out acts of regulations, standards and norms; guidance, constraints and incentives the behavior of the main players in the market; protect press supervision powers to guide the way of public opinion and methods.

3) Judicial indemnification. The law is strict principles and norms and the judicial specialized activities to use the law to carry out judicial matters, the maintenance of the spirit of the law and the interpretation of legal principles safeguarding the dignity and authority of the law, to effectively compensate for legal defects. It also require the Justice to maintain neutrality, independence, unity, professionalism, openness and authoritative.

Regulatory issues in the government investment projects, the judicial system should be necessary for stakeholders to provide a clear, clear judicial interpretation, when the relationship between the relevant parties to take legal action to adjust the trial should be able to make a fair and independent trial.

(2) Social security mechanism

The role of the social dimension of the indemnification mechanism is to protect the public oversight powers to achieve, mainly reflected in:

1) Disclosure mechanisms: The establishment of a sound variety of media channels, in an open, convenient and intuitive form of information to the citizens of the disclosure and the agent construction projects construction management.

2) Exchange mechanism: the establishment of sound public platform for the public to create and provide published, exchange and discuss different perspectives carrier.

(3)to guide mechanism: to guide citizens through a positive, well-intentioned, rational debate and seek common ground while reserving differences, to reach consistent in principle, to provide the public with reasonable channels to express their demands.

4)The education mechanisms: Education, guide and help citizens through multiple channels, using a variety of forms 
to safeguard their own rights, and the formation of positive and sustainable development of social ethics and values to guide the direction of social and economic development.

Obviously, the social dimension of supervision should be established on the basis of the public's right to know and the right to freedom of expression, it is necessary to get the dual support of the government and training units to realize truly.

(3) The employer indemnification mechanism

Employers safeguard mechanism role is to provide timely and effective information feedback for training institutions and government to make policy to ultimately improve the quality of higher education. The goal of higher education is to train highly qualified personnel for the community, the employing unit is the receiving end of these personnel, and the level of the quality of higher education requires a combination of training units' feedback to make a comprehensive analysis. Coordinated supervision of the quality of the higher education system of the chain, employer feedback is critical.

1) Information storage mechanism. Received higher education graduates, the employer should do a good job and the training unit information witching work, Stone they employ graduates information to the unit. The year's graduates after work, the employer should do the job of storage of information, including each performance appraisal of the graduates, the overall development situation. The employer should continue to improve this information storage mechanism to provide indemnification for its feedback mechanism.

2) Feedback mechanism. The employer timely feedback the stoned information to the training unit and the government, which can help the government and the training unit to analyze the quality of higher education, and to take effective measures to improve the quality of higher education.

\section{SUMMARY}

At present, China's higher education has become a popular education, how to protect its quality has become the key to its development. Collaborative regulatory of higher education system, including the training unit self-control system and multi-party participation in lateral system of supervision, can supervise and manage the whole process of higher education and guarantee the quality of higher education. To protect the effective implementation of the coordinated supervision system, this paper put forward the corresponding indemnification mechanisms. The effective indemnification mechanism can guarantee the implementation of the collaborative regulatory, which is the basis of the ultimate indemnification the higher education quality. However, this article on the content of specific indemnification mechanism is not comprehensive enough, but I believe that it can improve the inadequate of the indemnification mechanism after constant practice, which will better guarantee the quality of higher education in China in future.

\section{ACKNOWLEDGMENT}

This paper is sponsored by the special funding of Beijing Municipal Commission of Education for joint projects with North China Electric Power University of 2012.

The authors would like to acknowledge the supports by the Chinese National Nature Science Foundation of China (No. 71271085) and Beijing Twelfth Five Year Plan Project of philosophy and social sciences (No. 12JGB044).

\section{REFERENCES}

[1] Li Mao-rong. Popular Background constructs of higher education quality assurance mechanisms [J]. Journal of Chongqing Normal University Edition of Social Siences. 2010(03)

[2] Ren Cui-xiang, Liu Yun-wei. Students' psychological protection mechanism in the Popularization of Higher Education [J]. Journal of Tangshan Teachers College. 2010(04)

[3] Xiong Zhi-xiang, Kang Hong-fo. Higher Education Quality Assurance mechanism [J]. Research in Higher Education of Engineering. 2002(02)

[4] Liu Ning, Dong Xiu. College examination reform model and safeguard mechanisms J]. Journal of Shenyang Jianzhu University (Social Science). 2008(01)

[5] Yu Yang. University governance structure and the relationship between education quality assurance mechanism Exploration [J]. JiangsuHigherEducation. 2012(01)

[6] Wang Ming-xia. College professional education quality assurance mechanisms: A study based on analysis [J]. Modern Education Management. 2009(03)

[7] Sun Liu- ze. Seek the intersection of the "conflict" - quality assurance mechanisms in higher education management analysis [J]. China Market. 2009(09)

[8] Wang Wen-lu, Wen Qin-neng. Local colleges teaching quality monitoring system and guarantee mechanism construction [J]. Journal of Shaanxi University of Technology (Social Sciences). 2009(03) 